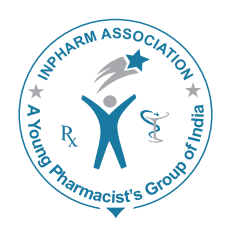

\title{
JVP
}

\section{Anticonvulsant activity of quinine in rat models of seizure in comparison with valproate and phenytoin}

\author{
BN Vallish ${ }^{1 *}$, Shyamal R Sinha², Abhijeet D Joshi², Avinash V Turankar ${ }^{3}$, \\ Sadiq B Patel ${ }^{2}$, Raj Kishore Mahato ${ }^{1}$
}

\author{
${ }^{1}$ Department of Pharmacology, Velammal Medical College Hospital \& Research Institute, Madurai, \\ Tamil Nadu, India, ${ }^{2}$ Department of Pharmacology, Grant Government Medical College \& Sir JJ Group \\ of Hospitals, Mumbai, Maharashtra, India, ${ }^{3}$ Department of Pharmacology, Government Medical College, \\ Nagpur, Maharashtra, India
}

\begin{abstract}
Background: Presently available anti-seizure drugs cannot control seizures in $20-40 \%$ epilepsy patients who develop refractory epilepsy. None of the currently available anti-seizure drugs targets hypersynchronization of epileptogenic impulses. Process of hypersynchronization involves gap junction (GJ) activity. Quinine blocks GJs, and prevents seizures in animal models. Since comparative studies were lacking, this animal study compared anticonvulsant activity of quinine with that of valproate and phenytoin. Materials and Methods: Seizures were induced in adult albino Sprague/Dawley rats $(n=72)$ using pentylenetetrazole (PTZ) and maximum electroshock (MES) methods, comparator drugs being valproate $(90 \mathrm{mg} / \mathrm{kg})$ and phenytoin $(27 \mathrm{mg} / \mathrm{kg})$, respectively. Quinine was given in three doses $(28,35$ and $42 \mathrm{mg} / \mathrm{kg})$. Results: Higher doses of quinine (35 and $42 \mathrm{mg} / \mathrm{kg}$ ) controlled PTZ seizures; efficacy was similar to valproate. MES seizures were not suppressed. Conclusion: Quinine has in-vivo anticonvulsant activity in rats in PTZ model at higher doses, but not in MES model in the doses tested.
\end{abstract}

Key words: Gap junctions, hypersynchronization, maximal electroshock, pentylenetetrazole

\section{INTRODUCTION}

Despite the availability of many antiepileptic drugs, around $20-40 \%$ of newly diagnosed epilepsy patients will end up with refractory epilepsy. ${ }^{1}$

\begin{tabular}{|c|c|}
\hline \multicolumn{2}{|c|}{ Access this article online } \\
\hline Journal Sponsor & \multirow[b]{2}{*}{$\begin{array}{l}\text { Website: } \\
\text { www.jyoungpharm.org }\end{array}$} \\
\hline \multirow{2}{*}{ www.phcog net } & \\
\hline & $\begin{array}{l}\text { DOI: } \\
\text { 10.5530/jyp.2014.3.6 }\end{array}$ \\
\hline
\end{tabular}

Pathophysiology of epilepsy includes two sequential events: (a) Generation of a locus of abnormally increased neuronal excitability; (b) spread of this hyperexcitability across the neurons through hypersynchronization. ${ }^{2}$ None of the current anti-seizure drug targets the latter mechanism.

Gap junctions (GJs), which mediate electrotonic synaptic communication between neurons are involved in the process of hypersynchronization. ${ }^{3}$ The functional units of GJs are connexins (Cxs) (Figure 1)..$^{4}$ Of the $21 \mathrm{Cx}$ subtypes described in humans, $\mathrm{Cx}-36$ is the major neuronspecific $\mathrm{Cx}$. Cx-36 is involved in seizure pathogenesis and 


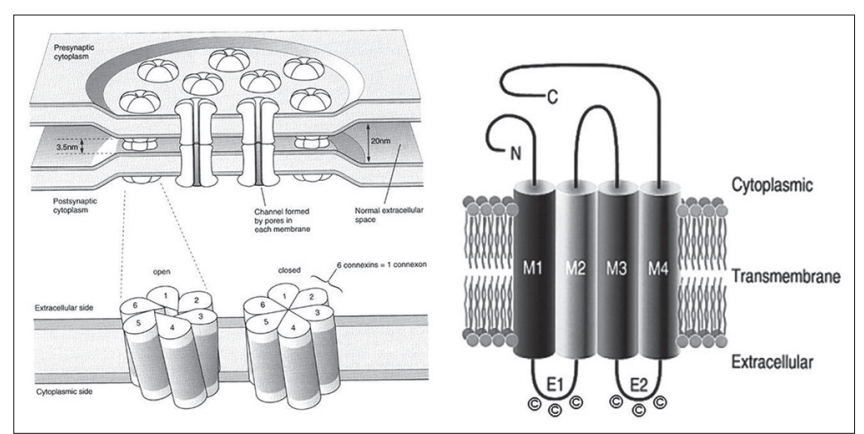

Figure 1: Schematic drawing of gap junction channels ${ }^{4}$

has been associated with juvenile myoclonic epilepsy. ${ }^{3}$ Quinine is a selective and reversible blocker of $\mathrm{Cx}-36 .^{5}$

Various studies have documented in-vitro and in-vivo anticonvulsant activity of quinine in animal models. ${ }^{3,6-9}$ However, there is a paucity of data wherein the anticonvulsant activity of quinine is compared with drugs currently used in treating epilepsy.

\section{MATERIALS AND METHODS}

This randomized, prospective, controlled, openlabelled animal study was conducted in Department of Pharmacology, Grant Government Medical College and Sir JJ Group of Hospitals, Mumbai, after obtaining Institutional Animal Ethics Committee approval.

Healthy albino Sprague-Dawley rats $(n=72)$ of either sex weighing 150-200 g, inbred in the institutional animal house, were used for the study. The animals were given care as per Committee for the Purpose of Control and Supervision of Experiments on Animals guidelines. ${ }^{10}$

Normal saline vehicle was used to prepare drug solutions of quinine (N.I Pharmaceuticals, India), valproate (Sun, India), phenytoin (Abbott, India), and pentylenetetrazole (PTZ) (Sigma, USA). The three doses of quinine used in the study $(28,35$ and $42 \mathrm{mg} / \mathrm{kg})$ were calculated from doses used in a similar study where mice were used; $, 0,11$ the dose of PTZ $(90 \mathrm{mg} / \mathrm{kg}$ ) was the same as used in a similar study. ${ }^{8}$ Doses of valproate and phenytoin $(90 \mathrm{mg} / \mathrm{kg}$ and $27 \mathrm{mg} / \mathrm{kg}$ respectively) were extrapolated from their average therapeutic dose in humans $(1000 \mathrm{mg}$ and $300 \mathrm{mg}$ respectively). ${ }^{11,12}$ PTZ was administered subcutaneously into the scruff of the neck; all the other drugs were administered intraperitoneally.

PTZ model: ${ }^{13}$ The animals were injected drugs/vehicle as per study groups. Thirty minutes later PTZ was administered, and the animals were observed for 30 minutes.
The occurrence of clonic seizure for more than 5 seconds was taken as a positive seizure response; abolition of clonic seizure was considered as protection against PTZ seizures. Seizure occurrence (present/absent), seizure latency (time for seizure onset) in seconds, and duration of the clonic phase of the seizure in seconds were recorded.

Maximal electroshock (MES) model: ${ }^{13}$ Well before the experiment, animals were acclimatized to the feel of ear-clip electrodes; rats that struggled excessively were discarded. The electroconvulsiometer (Bijou, Prasad Scientific) was calibrated at $150 \mathrm{~mA} / 100 \mathrm{~V} / 0.2 \mathrm{~s}$. The animals were injected drugs/vehicle as per study groups. Thirty minutes later, the rats were subjected to electric shock, and the resultant convulsions were timed. The occurrence of a hind limb tonic extension (HLTE) was taken as a positive response for MES; abolition of HLTE was taken as protection against MES seizures. HLTE occurrence and duration of HLTE in seconds were recorded.

Statistical analysis was performed using "Graphpad Prism 5" (San Diego, California, USA). For comparison between groups, one-way ANOVA was used with post-hoc Tukey's test. $P<0.05$ was considered as significant.

\section{RESULTS}

\section{PTZ model (Table 1)}

\section{Seizure occurrence}

Seizures were seen in all the animals in P0 group and PC (control group in the PTZ arm) group. Valproate prevented seizure occurrence in $4 / 6$ rats $(66.67 \%$ seizure protection). Quinine $35 \mathrm{mg} / \mathrm{kg}$ and $42 \mathrm{mg} / \mathrm{kg}$ prevented seizures in $2 / 6$ and $3 / 6$ rats, respectively $(33.33 \%$ and $50 \%$ seizure protection respectively). Quinine $28 \mathrm{mg} / \mathrm{kg}$ did not prevent seizure occurrence.

\section{Seizure latency and duration}

There was no significant difference in the mean seizure latency and mean seizure duration between the two control groups; normal saline group was considered as a control group for further analysis.

Compared with control, valproate significantly prolonged seizure latency and shortened seizure duration $(P<0.001)$. Quinine $28 \mathrm{mg} / \mathrm{kg}$ did not prolong seizure latency or shorten seizure duration significantly $(P>0.05)$; the other two doses showed significant prolongation of seizure latency $(P<0.001$ in both doses $)$ and shortening of seizure duration (35 mg/kg: $P<0.01 ; 42 \mathrm{mg} / \mathrm{kg}: P<0.001)$. 
Vallish, et al:: Anticonvulsant activity of quinine in rat seizure models

Table 1: Seizure occurrence, mean seizure latency and duration in PTZ model

\begin{tabular}{llccccc}
\hline Group & Drug & Seizure occurrence & Seizure latency $(\mathbf{s e c})^{*}$ & $\boldsymbol{P}$ value & Seizure duration (sec) & $\boldsymbol{P}_{\text {value }}$ \\
\hline PC & Control: Normal saline & $6 / 6$ & $129.00 \pm 52.66$ & - & $38.33 \pm 15.65$ & - \\
P0 & No drug & $6 / 6$ & $127.67 \pm 52.12$ & $>0.05$ & $43.17 \pm 17.62$ & $>0.05$ \\
PS & Standard: Valproate $90 \mathrm{mg} / \mathrm{kg}$ & $2 / 6$ & $839.67 \pm 342.79$ & $<0.001^{*}$ & $8.67 \pm 3.54$ & $<0.001^{*}$ \\
P1 & Quinine $28 \mathrm{mg} / \mathrm{kg}$ & $6 / 6$ & $264.17 \pm 107.85$ & $>0.05$ & $37.33 \pm 15.24$ & $>0.05$ \\
P2 & Quinine $35 \mathrm{mg} / \mathrm{kg}$ & $4 / 6$ & $633.17 \pm 258.49$ & $<0.001^{*}$ & $13.83 \pm 5.65$ & $<0.01^{*}$ \\
P3 & Quinine 42 mg/kg & $3 / 6$ & $711.17 \pm 290.33$ & $<0.001^{*}$ & $10.67 \pm 4.35$ & $<0.001^{*}$ \\
\hline
\end{tabular}

$N=6$ in each group. One-way ANOVA followed by Tukey's test."Mean \pm SEM, *Statistically significant (comparison with PC group), SEM: Standard error of the mean, PTZ: Pentylenetetrazole

When the seizure latency and seizure duration seen with valproate were compared with those observed with the three doses of quinine, there was a significant difference with quinine at $28 \mathrm{mg} / \mathrm{kg}(P<0.001)$; however, the difference seen with the other two doses of quinine were not significant (Figure 2a and b).

There was a significant difference between mean seizure latency and seizure duration values of the $28 \mathrm{mg} / \mathrm{kg}$ (P1) group and the other two quinine groups (seizure latency: $P<0.01$ with $35 \mathrm{mg} / \mathrm{kg}$ group; all other comparisons: $P<0.001)$, but there was no significant difference between the mean values of $35 \mathrm{mg} / \mathrm{kg}$ (P2) and $42 \mathrm{mg} / \mathrm{kg}$ (P3) groups (Figure 2c and d).

\section{MES model (Table 2)}

\section{Seizure occurrence}

Phenytoin (MS group) prevented seizure occurrence in $4 / 6$ rats $(66.67 \%$ seizure protection). In all the other groups, seizures were observed in all animals.

\section{Seizure duration}

Significant difference was not seen between mean seizure duration between the two control groups; normal saline group was considered as a control group for further analysis.

Compared with control, phenytoin significantly reduced HLTE duration $(P<0.001)$. However, none of the three doses of quinine caused a significant reduction in HLTE duration.

There was no significant difference in HLTE duration between the three groups of quinine ( $P>0.05$ in all cases).

\section{DISCUSSION}

Quinine is a reversible blocker of GJs formed by $\mathrm{Cx}-$ 36, and has a low selectivity for $\mathrm{Cx}-50$, but not other Cx protein subtypes. ${ }^{5}$ Studies have demonstrated that quinine suppresses ictal activity without affecting normal neuronal function in both in-vitro (rat hippocampal slice preparation $)^{7}$ and in-vivo (4-aminopyridine induced epilepsy model $)^{3}$ conditions. Further, trimethylamine, a specific opener of GJ channels negates quinine's seizure protective activity. ${ }^{8}$ Thus, the anticonvulsant activity seen with quinine is most probably due to its effects on the GJs.

In our study, we found that quinine at doses of $35 \mathrm{mg} / \mathrm{kg}$ and $42 \mathrm{mg} / \mathrm{kg}$, but not $28 \mathrm{mg} / \mathrm{kg}$ protects rats against PTZ-induced seizures, and the efficacy was comparable to valproate. Similar to our study, Nassiri-Asl et al. had reported that higher doses (50 and $60 \mathrm{mg} / \mathrm{kg}$ in mice), but not lower doses (20,30 and $40 \mathrm{mg} / \mathrm{kg}$ in mice), of quinine had anticonvulsant activity in PTZ model. ${ }^{6}$ Our study did not demonstrate seizure protection by any of the three doses of quinine in the MES model. Wambebe et al. had also similarly reported that quinine did not have anticonvulsant activity in MES model in mice. ${ }^{?}$

Thus, quinine appears to have anticonvulsant activity in the PTZ model at higher doses, but not in the MES model. This differential efficacy of quinine can be accounted for by two reasons:

a. Quinine might be having activity in MES model at doses that are different from those considered in the present study.

b. Among the various drugs known to block GJs, carbenoxolone is known to be a non-specific GJ inhibitor ${ }^{14}$ Carbenoxolone is reported to control seizures induced by both MES and PTZ models. ${ }^{15}$ Quinine, on the other hand, inhibits only those GJs that are formed by $\mathrm{Cx}-36$ and $\mathrm{Cx}-50 .{ }^{5}$ It might be possible that the pathophysiology of MES-induced seizures involves GJs formed by Cxs other than Cx-36 and Cx-50.

Studies with a larger sample size, and a wider range of doses of quinine, can confirm its usefulness in PTZ model, and explore its potential in the MES model and in other seizure models as well.

Journal of Young Pharmacists Vol 6 • Issue 3 • Jul-Sep 2014 

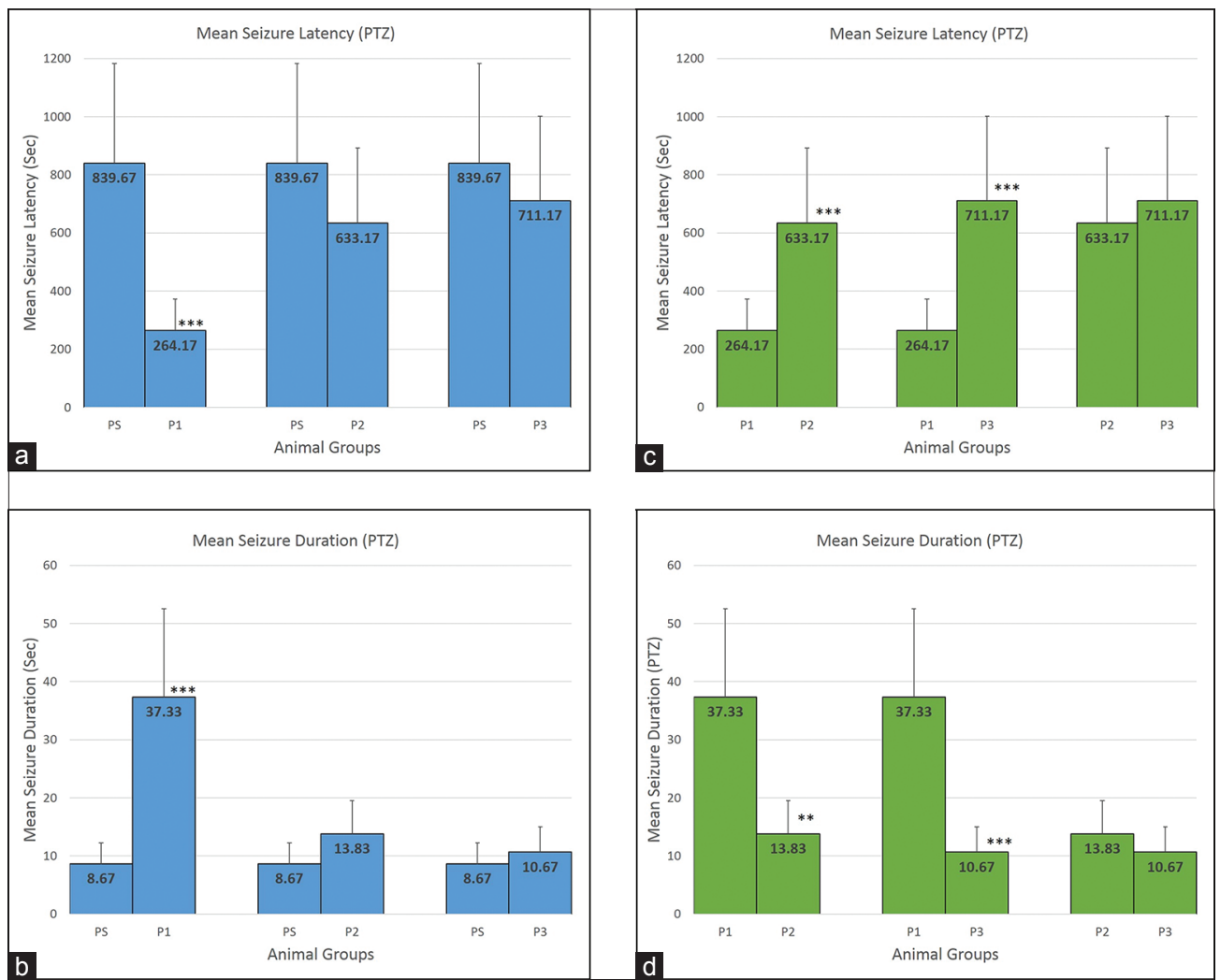

Figure 2: Comparison of mean seizure latency and duration in pentylenetetrazole group. (a) Mean seizure latency and (b) mean seizure duration of quinine groups compared with standard; (c) mean seizure latency and (d) mean seizure duration of three quinine groups compared among themselves

Table 2: Seizure occurrence and mean HLTE duration in MES model

\begin{tabular}{llccc}
\hline Group Drug and dose & $\begin{array}{c}\text { Seizure } \\
\text { occurrence }\end{array}$ & $\begin{array}{c}\text { HLTE duration } \boldsymbol{P} \text { value } \\
\text { (sec) }\end{array}$ & \\
\hline MC & $\begin{array}{l}\text { Control: Normal } \\
\text { saline }\end{array}$ & $6 / 6$ & $11.00 \pm 4.49$ & - \\
M0 & No drug & $6 / 6$ & $11.17 \pm 4.56$ & $>0.05$ \\
MS & $\begin{array}{l}\text { Standard: Phenytoin } \\
\text { 27 mg/kg }\end{array}$ & $2 / 6$ & $2.67 \pm 1.01$ & $<0.001^{*}$ \\
M1 & Quinine 28 mg/kg & $6 / 6$ & $10.00 \pm 4.08$ & $>0.05$ \\
M2 & Quinine 35 mg/kg & $6 / 6$ & $9.50 \pm 3.88$ & $>0.05$ \\
M3 & Quinine 42 mg/kg & $6 / 6$ & $9.33 \pm 3.81$ & $>0.05$ \\
\hline
\end{tabular}

HLTE: Hind limb tonic extension, SEM: Standard error of the mean, MES: Maximum electroshock. $N=6$ in each group. One-way ANOVA followed by Tukey's test. "Mean \pm SEM, *'Statistically significant (comparison with MC group)

An ideal candidate antiepileptic drug should have minimal adverse effects for ensuring better patient compliance. Though quinine is associated with many side-effects, ${ }^{14}$ its novel anticonvulsant mechanism cannot be neglected keeping in mind the ever-increasing problem of refractory epilepsy. In this context, quinine might be useful as a rescue drug for refractory seizures and treatment-resistant status epilepticus, pending results from appropriate studies in animal models. Another hope for the future is that newer molecules that have the anticonvulsant properties of quinine without its adverse effects be developed.

\section{CONCLUSION}

Quinine has anticonvulsant activity in albino SpragueDawley rats in the PTZ seizure model (at higher doses) but not in the MES seizure model, and that this anticonvulsant activity is comparable to that seen with valproate.

\section{ACKNOWLEDGEMENTS}

The authors acknowledge the cooperation extended by the teaching and non-teaching staff at the Department of Pharmacology at Grant Govt Medical College, Mumbai.

\section{Conflict of Interest: None.}

\section{REFERENCES}

1. French JA. Refractory epilepsy: Clinical overview. Epilepsia 2007;48 Suppl 1:3-7.

2. Engelborghs S, D'Hooge R, De Deyn PP. Pathophysiology of epilepsy. Acta Neurol Belg 2000;100:201-13.

3. Gajda Z, Szupera Z, Blazsó G, Szente M. Quinine, a blocker of neuronal cx36 channels, suppresses seizure activity in rat neocortex in vivo. Epilepsia 2005;46:1581-91.

4. Söhl G, Willecke K. Gap junctions and the connexin protein family. Cardiovasc Res 2004;62:228-32.

5. Srinivas M, Hopperstad MG, Spray DC. Quinine blocks specific gap junction 
channel subtypes. Proc Natl Acad Sci U S A 2001;98:10942-7.

6. Nassiri-Asl M, Zamansoltani F, Torabinejad B. Antiepileptic effects of quinine in the pentylenetetrazole model of seizure. Seizure 2009;18:129-32.

7. Bikson M, Id Bihi R, Vreugdenhil M, Köhling R, Fox JE, Jefferys JG. Quinine suppresses extracellular potassium transients and ictal epileptiform activity without decreasing neuronal excitability in vitro. Neuroscience 2002;115: 251-61.

8. Nassiri-Asl M, Zamansoltani F, Zangivand AA. The inhibitory effect of trimethylamine on the anticonvulsant activities of quinine in the pentylenetetrazole model in rats. Prog Neuropsychopharmacol Biol Psychiatry 2008;32:1496-500.

9. Wambebe C, Sokomba E, Amabeoku G. Effect of quinine on electroshock and pentylenetetrazol-induced seizures in mice. Prog Neuropsychopharmacol Biol Psychiatry 1990;14:121-7.
10. CPCSEA Guidelines for Laboratory Animal Facility. Available from: http:// icmr.nic.in/bioethics/final_cpcsea.pdf. [Last cited on 2014 Feb 26].

11. Ghosh MN. Fundamentals of Experimental Pharmacology. $3^{\text {rd }}$ ed. Kolkata: Hilton \& Company; 2002.

12. Lowenstein DH. Seizures and epilepsy. In: Longo DL, Kasper DL, Hauser SL, Jameson JL, Loscalzo J, Fauci AS, editors. Harrison's Principles of Internal Medicine. $18^{\text {th }}$ ed. New York: McGraw Hill; 2011. p. 3251-69.

13. Mittal R. Antiepileptics. In: Gupta SK, editor. Drug Screening Methods. $2^{\text {nd }}$ ed. New Delhi: Jaypee Brothers Medical Publishers; 2009. p. 400-22.

14. Spray DC, Rozental R, Srinivas M. Prospects for rational development of pharmacological gap junction channel blockers. Curr Drug Targets 2002;3:455-64.

15. Hosseinzadeh H, Nassiri Asl M. Anticonvulsant, sedative and muscle relaxant effects of carbenoxolone in mice. BMC Pharmacol 2003;3:3. 